\title{
The influence of relationship beliefs on gift giving
}

\author{
Dipankar RAI \\ Le Moyne College, Syracuse, NY, USA \\ e-mail: raid@lemoyne.edu \\ Chien-Wei (Wilson) LIN \\ State University of New York at Oneonta, Oneonta, NY, USA \\ e-mail: wilson.lin@oneonta.edu \\ JungHwa (Jenny) HONG \\ University of Texas-Tyler, Tyler, TX, USA \\ e-mail: jhong@uttyler.edu \\ George KULICK \\ Le Moyne College, Syracuse, NY, USA \\ e-mail: kulick@lemoyne.edu
}

\begin{abstract}
People have fundamental beliefs about what constitutes a good relationship, known as implicit theories of relationship, where some people have destiny beliefs whereas others have growth beliefs. People with destiny beliefs believe that potential partners are meant either for each other or not, whereas people with growth beliefs believe that successful relationships are cultivated and developed. This research shows that different implicit theories of relationship influence consumers' gift choice to their significant others. We demonstrate, through two studies, that consumers with destiny beliefs prefer giving gifts that are more feasible in nature, whereas consumers with growth beliefs prefer giving gifts that are more desirable in nature. We show that this effect is mediated by desirability-feasibility considerations. Specifically, consumers with destiny beliefs focus on feasibility considerations, which leads them to choose a highly feasible gift. Conversely, consumers with growth beliefs focus on desirability considerations, which leads them to choose a highly desirable gift. We also discuss the theoretical and managerial implications of our research.
\end{abstract}

Keywords: consumer behavior, implicit theory of relationship, feasibility, desirability, gift giving.

Please cite the article as follows: Rai, D., Lin, C.W., Hong, J. and Kulick, G. (2017), "The influence of relationship beliefs on gift giving", Management \& Marketing. Challenges for the Knowledge Society, Vol. 12, No. 4, pp. 697-709. DOI: 10.1515/mmcks-2017-0040.

\section{Introduction}

The tradition of gift-giving has become a ubiquitous part of consumers' lives where gifts serve as a way to create and maintain social bonds that are a central component in the society (Baskin et al., 2014). In the United States, consumers spend around $\$ 131.3$ billion dollars per year purchasing gifts, which represents about $10 \%$ of the retail market (Research and Markets, 2015). Therefore, understanding the phenomenon of gift-giving is important to marketing researchers. Recent research has investigated the various factors that influence gift-giving (Ward and Broniarczyk, 2016; Baskin et al., 2014; Gino and Flynn, 2011). However, there is scant research investigating the phenomenon of gift-giving in the context of romantic relationships. Recent research in marketing has shown that various 
factors such as attachment orientations, relationship satisfaction, and relationship commitment influence gift giving behavior (Nguyen and Munch, 2011). Nonetheless, research has not considered whether consumers' gift-giving behavior is driven by their belief of what constitutes a good relationship. Research in social psychology shows that people have two different beliefs about the nature of relationships known as the implicit theories of relationship which are either growth or destiny beliefs (Knee, 1998). People who have destiny beliefs hold that relationships are destined and assume that potential partners are meant either for each other or not. People with growth beliefs believe that relationships are characterized by growth and assume that successful relationships are cultivated and developed. In this article, we investigate how the different implicit theories of relationship influence consumers' gift giving behavior. Since romantic relationships are an important component of consumers' lives, understanding the role of implicit theories of relationships on consumer decisions is an important area to explore for marketing researchers. Therefore, explicating how implicit theories of relationships influence gift giving behavior helps us advance our understanding of the impact of implicit theories of relationship on consumer decisions.

Across two experiments, we show that consumers' implicit theories of relationship influence their choice of gifts to their significant others. Specifically, consumers who have growth beliefs prefer giving gifts that are more desirable in nature whereas consumers who have destiny beliefs prefer giving gifts that are more feasible in nature. Furthermore, the influence of implicit theories of relationship on preference of gifts is mediated by desirability-feasibility considerations. Specifically, growth beliefs influence consumers to focus on desirability considerations, which lead them to prefer giving highly desirable gifts. On the other hand, destiny beliefs influences consumers to focus on feasibility considerations, which lead them to prefer giving highly feasible gifts.

The rest of the article is organized as follows. First, we review the literature on implicit theories of relationship and gift giving. Second, we propose hypotheses that highlight the impact of implicit theories of relationships and gift giving behavior. Third, we present two experiments that test our hypotheses and provide evidence for the underlying process. Finally, we discuss the theoretical and practical implications.

\section{Theoretical background}

\section{Gift-giving}

Research in gift-giving suggests that gifts serves four different functions (Belk, 1979). Gifts serves as (1) a symbolic communication between the giver and the recipient, (2) a social exchange which aids in building and maintaining interpersonal relationships, (3) an economic exchange which serves as obligatory reciprocal exchanges, and (4) as a socializer which helps parents teach children about the customs of society. In romantic relationships, gifts are used to start relationships (Belk and Coon, 1991), to mend unstable relationships (Caplow, 1982), and to gain attention of the recipients (Ruth et al., 2004). Therefore, in a romantic relationship, gifts serve as a symbolic communication and a social exchange between partners. Therefore, gifts serve as a signal that show relational intimacy between the giver and recipient and gift givers invest time, money and energy in this purchase. The resources dedicated to procure a gift serve as social signals and express that the gifts are more than mere objects intended to satisfy recipients (Prendergast and Stole, 2001). 


\section{Implicit theories of relationship and gift-giving}

Research in implicit theories of relationships show that people either have destiny beliefs or growth beliefs (Knee, 1998). Research has shown that these beliefs are conceptually distinct from each other (Knee et al., 2001).

Destiny belief in relationships holds that people are either destined to be together or not. Therefore, people with destiny beliefs focus on the initial stage of the relationship and believe that initial compatibility is a signal that they have found their perfect mate. If they are not initially compatible with their partner, people with destiny beliefs will assume that the relationship with that partner was not meant to be. This leads them to disengage and distance themselves from the relationship when they face negative relationship events. In other words, destiny belief leads people to test potential partners relatively quickly and moving on because they believe that a good relationship is meant to be and needs to be successful without putting much effort in the relationship. Additionally, since destiny beliefs make people focus on compatibility with partners, they don't believe that exerting effort in improving the relationship security and satisfaction will be successful (Hui et al., 2012). Growth belief in relationships holds that people are successful by working through obstacles with their significant other and growing closer. People with growth beliefs emphasize less on initial compatibility and focus more on understanding and developing closeness to their partner. This leads them to adopt coping strategies that help them to solve problems and grow from experiences when they face negative relationship events. They are likely to view negative events as opportunities for increased understanding between partners (Knee et al., 2001). In other words, growth belief leads people to be more committed and have a long-term approach to dating because they believe that a good relationship only occurs by putting in effort in the relationship to understand each other. Additionally, since growth beliefs make people focus on developing closeness with their partner, they believe that exerting effort improves relationship security and satisfaction (Hui et al., 2012). Therefore, destiny beliefs lead people to believe that exerting effort indicates a lack of compatibility with their partner, whereas growth beliefs lead people to believe that exerting effort is a recipe for building a good relationship. We suggest that this aspect of destiny and growth belief influences consumers' gift-giving behavior to their significant other.

Research in gift-giving shows that gift choices involve a tradeoff between two important dimensions: desirability and feasibility (Baskin et al., 2014). Desirability is the value of the end state of an action whereas feasibility is the ease of achieving the desired outcome (Liu, 2008). In other words, desirability corresponds to the rewards of the action that motivate people to pursue the action, whereas feasibility corresponds to the costs and constraints associated with pursuing the action. Research has shown that in the gift giving context (Baskin et al., 2014), desirability is related to the main components of the gift and refers to the quality of the gift item. Feasibility, on the other hand, is related to the peripheral components of the gift and refers to the convenience of being able to consume the gift.

Since destiny belief leads consumers to think that exerting effort indicates a lack of compatibility, we argue that destiny belief will make consumers more sensitive about the effort required to consume the gift item. This will make them think more about the ease and convenience of using the gift item, i.e., the feasibility considerations of the gift. Therefore, we propose that consumers with destiny belief will purchase a gift for their significant other that is easier to consume. In other words, destiny belief will motivate 
consumers to purchase a gift item for their significant other that is more feasible in nature. Since growth belief leads consumers to think that exerting effort is a recipe for good relationship, we argue that growth belief will make consumers more sensitive about the benefits received after consuming the gift item rather than the effort required to consume the gift item. This makes them think more about the central aspects of the gift, i.e. the desirable considerations of the gift. Therefore, we propose that consumers with growth beliefs will purchase a gift for their significant other that is more desirable in nature. Formally, we hypothesize:

H1: Consumers' implicit theories of relationship influences their gift-giving preference to their significant others: Consumers with destiny beliefs prefer to give highly feasible gifts whereas consumers with growth beliefs prefer to give highly desirable gifts.

H2: Desirability-feasibility considerations mediate the influence of the implicit theories of relationship on gift-giving where consumers with destiny beliefs focus on feasibility considerations whereas consumers with growth beliefs focus on desirability considerations.

\section{Study 1}

Study 1 examined the main effect of implicit theories of relationship on gift giving preference. Specifically, we expected consumers with destiny beliefs would prefer giving a highly feasible gift, i.e, a gift that is higher on feasibility related aspects and lower on desirability related aspects, whereas consumers with growth beliefs will prefer giving a highly desirable gift, i.e., a gift that is higher on desirability related aspects and lower on feasibility related aspects (H1).

\section{Method}

We randomly recruited seventy undergraduate students (50\% female) from a public university in the United States to participate in an online study in exchange for partial course credits. Four students failed to complete the attention test and were excluded from the analyses $(\mathrm{N}=66)$. This sample size is adequate because maintaining power at 80 in multiple regression requires a minimum sample of 50 observations for most research solutions (Hair et al., 1998). Also, our sample size is at least 15 times larger than the number of variables being considered (Roscoe, 1975).

Participants were asked to participate in two unrelated studies to mask the relationship between the implicit theories of relationships measure and the subsequent scenario. In the first study, participants filled out the eight items Implicit Theories of Relationship Scale (Knee et al., 2003). Four items measured growth beliefs regarding the ways in which relationships develop over time and how hard work, challenges, and conflict contribute to the success of the relationship. For example, we measured growth beliefs by using items such as these: "Challenges and obstacles in a relationship can make love even stronger." Four items measured destiny beliefs regarding the ways in which compatibility and signs from the start of the relationship may be indicative of the success or failure of that relationship. For example, we measured destiny beliefs by using items such as these: "Potential partners are either compatible or they are not." Respondents expressed their agreement to four statements reflecting growth beliefs and four statements representing destiny beliefs, anchored by a seven-point scale (strongly disagree (1)/strongly agree (7)). The same measure has been used by prior researchers (Knee et al., 2003; Cobb et al., 2013). 
In the second study, participants were asked to imagine that they have been in a relationship with a significant other for some time now. Next, they were asked to imagine a gift-giving scenario where they had to buy a gift for their significant other for a birthday occasion. In the scenario, participants had to choose between two gift certificates of two different restaurants (Baskin et al., 2014). Specifically, Restaurant A was a highly rated Italian restaurant (30/30 rating in Zagat's restaurant guide) an hour drive away, which was considered highly desirable but not very feasible. Restaurant B was an ordinary Italian restaurant (15/30 rating in Zagat's restaurant guide) a 5-minute drive away, which was considered highly feasible but not very desirable. It was specifically mentioned that these distances were in reference to the receiver and the gift certificates were equivalent in price at both restaurants. They were then asked to provide their preferences for buying the gift certificates for Restaurant A and Restaurant B with 7-point scales (prefer restaurant B (1)/prefer restaurant A (7)) for their significant others. Finally, participants provided information on their gender, age, and household income which served as controls for our study.

\section{Results}

We averaged responses to the growth belief and destiny belief items to create two separate scores (growth $\alpha=.81$, destiny $\alpha=.72$ ). We also created an overall implicit theory of relationship score to capture the dominance of one relationship belief over the other by subtracting participants' destiny belief score from their growth belief score. Thus, higher scores indicate a relatively greater belief in growth, and lower scores indicate a relatively greater belief in destiny in relationships.

\section{Main effect analysis}

To test the first hypothesis, we regressed implicit theories of relationship scores on the gift giving preference. As expected, results showed that participants with growth beliefs prefer a highly desirable gift whereas participants with destiny beliefs prefer a highly feasible gift $(\beta=.32, \mathrm{t}=1.92, p=.06)$. Thus, $\mathrm{H} 1$ is supported. We then ran multiple regression with gift giving preference as the dependent variable and the implicit theories of relationship and the covariates (i.e., gender, age, and income) as the independent variables. The main effect of implicit theories of relationship was significant $(\beta=.33, t=2.02, p<.05)$. None of the covariates were significant $(p s>.05)$. Therefore, the covariates did not account for our findings.

\section{Discussion}

Study 1 shows that participants with growth beliefs prefer buying highly desirable gifts whereas participants with destiny beliefs prefer buying highly feasible gifts for their significant others. Although this study provides initial evidence that implicit theories of relationship influence consumers' gift giving preferences, it is not without limitations. First, this study measured participants' implicit theories of relationship. Therefore, we examined the spontaneous interpretations of gift giving preferences as a function of implicit theories of relationship. However, this could have allowed for unobservable confounds to affect our results. We address this limitation in Study 2 by manipulating participants' implicit theories of relationship instead of measuring them. Second, we measured the underlying mechanism of the effect where participants with growth beliefs focus more on the desirability considerations whereas participants with destiny beliefs focus more on the 
feasibility consideration of the gift. Third, in addition to collecting demographic information, we measured participants' time pressure, money pressure, and eating out habits which served as control variables. Finally, we recruited our participants from Amazon Mechanical Turk (MTurk) to generalize our findings beyond the student population.

\section{Study 2}

This study had four objectives. First, to test the robustness of the results and explicate the causality of the prediction, we manipulated implicit theories of relationship instead of measuring them. Second, we examined if desirability-feasibility consideration was mediating the effect. Third, Study 2 employed several additional measures - using a scale of time and money pressures and the frequency of eating out - to test whether our findings can be attributed to these variables. Finally, we recruited participants via MTurk to check if our results generalize to consumers who are not students.

\section{Method}

One hundred and twelve Amazon Mechanical Turk (MTurk) participants from U.S (50\% female; Mage $=40$ ) participated in the survey in exchange for a small payment. Participants were randomly assigned to either growth beliefs or destiny beliefs condition in a single factor design. Our sample size is adequate because prior research suggested that experimental research should have sample of 30 observations per group (Roscoe, 1975). The MTurk participant pool is considered to be reliable for experimental research. It provides a better representation of the general population than traditional convenience student samples (Buhrmester et al., 2011; Goodman et al., 2013). Participants were assigned to either growth beliefs or destiny beliefs condition in a single factor design. Participants were first asked to take part in two ostensibly unrelated studies. The first study consisted of priming participants with growth beliefs or destiny beliefs (adapted from Elliott and Dweck, 1988). Specifically, participants were instructed to read a short article. Participants were told that the article was based on a recent research done by a relationship expert. We created two fictitious articles published in the New York Times that were similar in length and style. One article compellingly presented growth beliefs in relationship and the other compellingly portrayed destiny beliefs in relationship. The article about growth beliefs was titled "Challenges and obstacles make relationship last longer" and the article about destiny beliefs was titled "Relationships last longer only when you find compatible partners" (see Appendix). Participants wrote an essay supporting the article's viewpoint and answered the same implicit theories of relationship measure (Knee et al., 2003) as they did in Study 1, which served as manipulation checks. They then proceeded to the second part of the study.

In the second part of the study, we provided the same Study 1 gift giving scenario where participants had to choose between two different restaurants (Baskin et al., 2014). Participants indicated their relative preference between the restaurants anchored by " 1 (prefer restaurant B) $/ 7=$ (prefer restaurant A)". Restaurant A was highly desirable whereas restaurant B was highly feasible. Participants then reported their thoughts with statements associated with desirability and feasibility considerations. We measured participants' desirability consideration with scales such as: "were you thinking about the benefits of visiting the restaurant", "were you thinking about the quality of the food of the restaurant" $(\mathrm{r}=.73, \mathrm{p}<.001)$. We measured their feasibility consideration with the scales 
such as : "were you thinking about how difficult the drive will be to the restaurant", "were you thinking about how much effort it would take to drive to the restaurant") ( $\alpha=.97)$. We used a hundred-point scale anchored by "0 (not at all)/100 (very much so)."

To rule out the alternative explanation of the amount of time and money available, we employed an eight item 7 -point scale (1 = strongly disagree, 7 = strongly agree $)$ of felt money pressure (e.g., I look carefully to find the lower priced product; $\alpha=.51$; Andrews and Smith, 1996) and time pressure (e.g., I feel I need more hours in the day; $\alpha=.63$; Mittal, 1994). We also asked participants to report their frequency of eating out (i.e., how often do you usually eat out; $1=$ never, 7 = almost everyday). Finally, we measured their demographic variables (age, gender, and income). Since none of these demographic variables affected the results (ps $>.10$ ), we do not discuss them further.

\section{Results}

\section{Manipulation check}

We averaged the responses of the growth belief and destiny belief items to create two separate scores (growth belief $\alpha=.88$, destiny belief $\alpha=.79$ ). We subtracted participants' destiny beliefs score from their growth beliefs score to create an overall implicit theories of relationship score. Higher score indicated stronger growth beliefs whereas a lower score indicated stronger destiny beliefs. We conducted an independent sample t-test on the overall implicit theories of relationship measure between participants who were exposed to the growth beliefs manipulation and those who were exposed to the destiny beliefs manipulation. Results showed that participants in the growth beliefs condition agreed with statement regarding growth beliefs in relationship more than those in the destiny beliefs condition ( $\mathrm{M}_{\text {grow }}=1.7$ vs. $\mathrm{M}_{\text {destiny }}=-.11 ; \mathrm{t}=-5.94, p<.001$ ). Therefore, results show that our manipulation for implicit theories of relationship worked.

\section{Main effect analysis}

A one-way ANOVA on gift giving preference revealed that participants in the growth beliefs condition preferred the highly desirable but less feasible gift (restaurant A) over the highly feasible but less desirable gift (restaurant B) than the participants in the destiny beliefs condition (Mgrowth $=5.71$ vs. $\left.M_{\text {destiny }}=4.91 ; \mathrm{F}(1,110)=4.90, p<.05\right)$. Therefore, our results provided support for H1. The effect of growth (vs. destiny) beliefs remained significant with all the covariates (i.e., time and money pressures and the frequency of eating out) included $(F(1,107)=4.62, p<.05)$. The covariates did not account for our findings.

\section{Mediation analysis}

Consistent with our theorizing, there were significant effect of growth (vs. destiny) beliefs on desirability and feasibility considerations, but they took very different forms. One-way ANOVA revealed that participants in the growth beliefs condition reported greater desirability consideration than those in the destiny beliefs condition $\left(\mathrm{M}_{\text {grow }}=82.42\right.$ vs. $\left.M_{\text {destiny }}=71.75 ; \mathrm{F}(1,110)=4.85, p<.05\right)$. Similar analysis revealed that participants in the destiny beliefs condition reported greater feasibility consideration than those in the growth beliefs condition ( $M_{\text {destiny }}=45.2$ vs. $M_{\text {destiny }}=33.49 ; \mathrm{F}(1,110)=3.93, p=.05$, see Figure 1). 


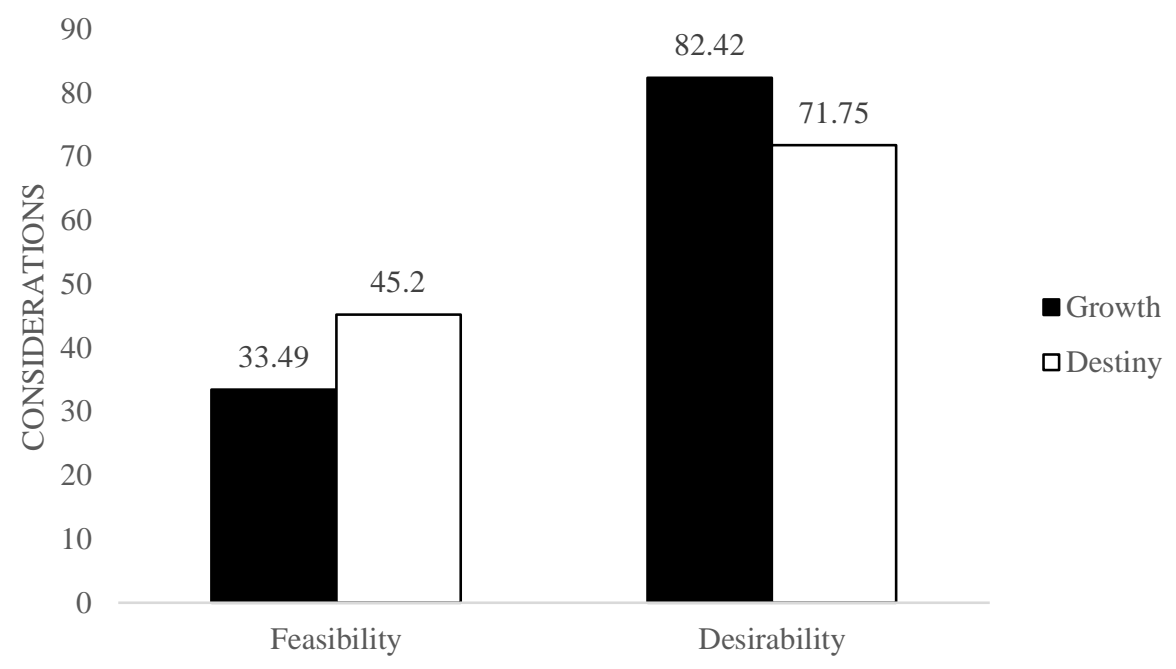

Figure 1. Effect of implicit theory of relationship on feasibility and desirability considerations (Study 2)

Source: Authors' own research results.

Next, the participants' feasibility consideration score was subtracted from their desirability consideration score to create a composite measure. A higher score reflected a stronger desirability consideration whereas a lower score reflected a stronger feasibility consideration. Mediation model using the PROCESS macro (Model 4; Hayes, 2013, see Figure 2) revealed that the effect of implicit theories of relationship on gift giving preference was mediated by desirability-feasibility consideration ( $\mathrm{ab}=.59,95 \% \mathrm{CI}=.17$ to 1.08 excluded 0). In the indirect path, a unit increase in growth beliefs increased the desirability consideration by 21.39 units $(a=21.39)$, suggesting that participants with growth beliefs reported a higher desirability than feasibility consideration. Thus, holding implicit theories of relationship constant, a unit increase in desirability consideration increased the preference for restaurant A (the highly desirable gift) by .03 units ( $b=.03)$. The direct effect $c(.22)$ was not significant $(p>.1)$, suggesting the indirect-only mediation (Zhao et al., 2010). In other words, desirability-feasibility consideration mediated the effect of participants' growth (vs. destiny) beliefs on the preference for highly desirable (vs. feasible) gifts. Therefore, results provided support for $\mathrm{H} 2$.

\section{a) Direct Path}

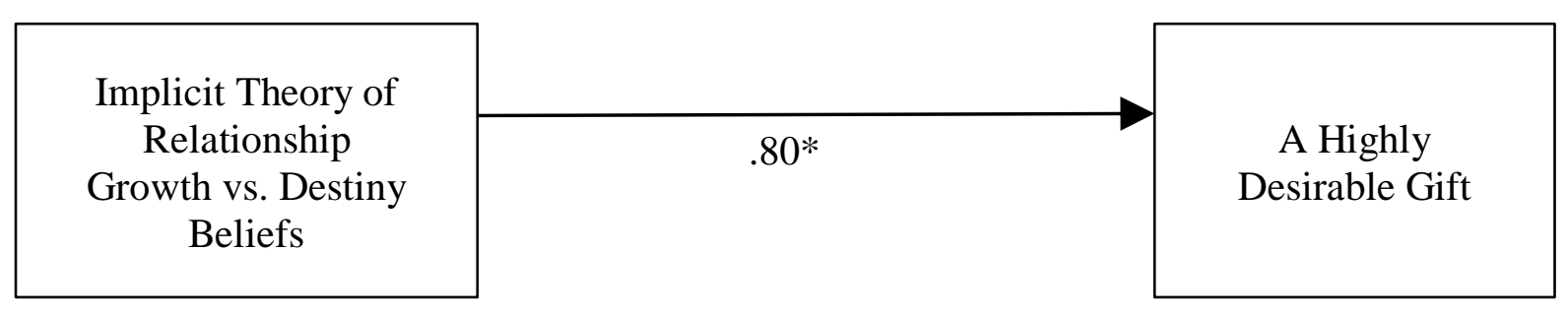


b) Mediated Path

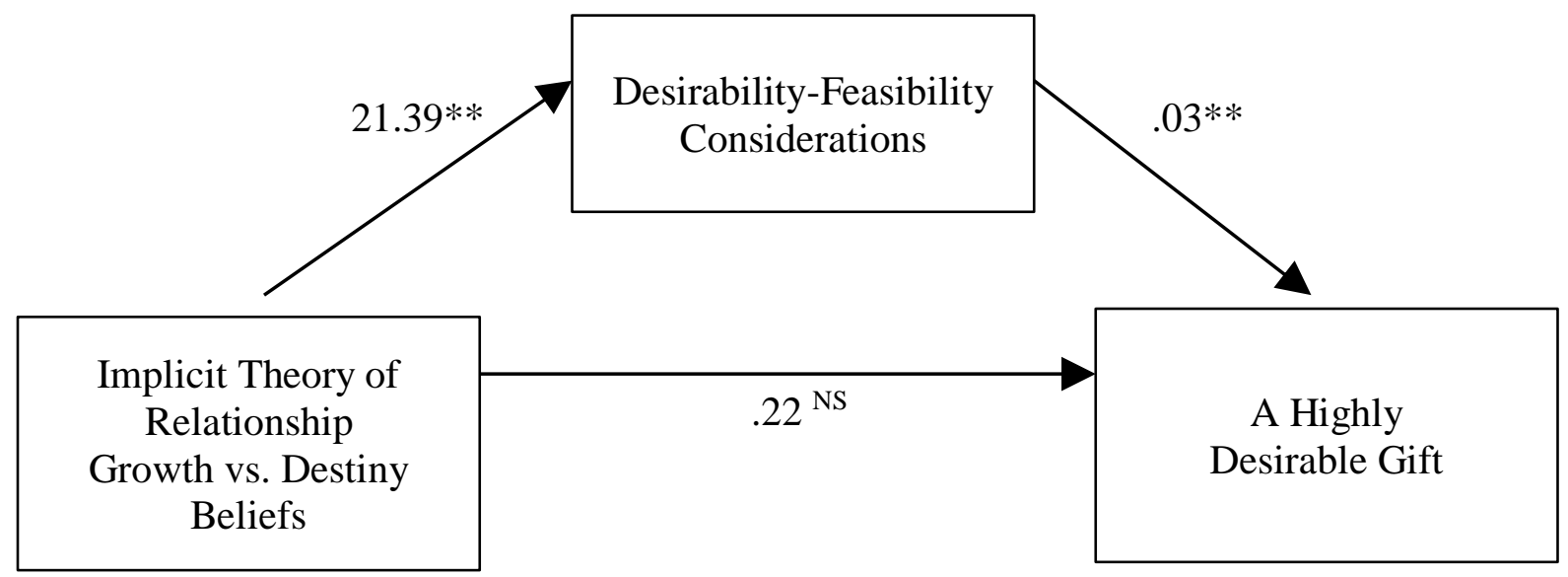

Figure 2. Mediation analysis (Study 2)

* indicates that $p$ value $<.05$ and ${ }^{* *}$ indicates that $p$ value $<.01$

Source: Authors' own research results.

\section{Discussion}

The above findings show that implicit theories of relationship influence consumers' gift giving preferences. We find that participants with growth beliefs prefer giving the highly desirable gifts whereas participants with destiny beliefs prefer giving highly feasible gifts. Furthermore, we find that desirability-feasibility considerations mediate this effect. Specifically, growth beliefs increase consumer's focus on desirability considerations of gift giving whereas destiny beliefs increase consumer's focus on feasibility considerations of gift giving. The findings also cast doubt on the potential alternative explanation of eating out habits and the time and money pressures faced by the participants.

\section{General Discussion}

In this research, we investigate the impact of different implicit theories of relationship on gift-giving behavior of consumers. Specifically, we show that consumers with destiny belief focus on the feasibility considerations of a gift when thinking about purchasing a gift for their significant others. This is because consumers with destiny belief are sensitive about the effort required to consume the gift item, which makes them think more about the ease and convenience of using the gift item. This leads them to choose a gift which is more feasible in nature. On the other hand, consumers with growth belief focus on the desirability considerations of a gift when thinking about purchasing a gift for their significant others. Since people with growth beliefs value exerting effort to be an important recipe for building a good relationship, they are more likely to think about the central aspects of the gift. This leads them to choose a gift which is more desirable in nature.

\section{Theoretical and managerial implications}

Our research offers several contributions. Research in construal level theory has identified a host of antecedents that lead to shifts in desirability and feasibility considerations (e.g., Trope and Liberman, 2010; Rai et al., 2016). Our findings add to this research by identifying implicit theories of relationship as an antecedent leading to these shifts in 
desirability-feasibility considerations. We show that destiny belief leads consumers to focus on feasibility considerations whereas growth belief leads them to focus on desirability considerations. Additionally, our findings extend the research on gift-giving by showing that implicit theories of relationship influence consumers' gift preferences.

Our research provides important practical implications for marketers. First, our findings suggest that marketers need to recognize that having a one-size fits all approach when it comes to gifts may not be successful. Marketers need to recognize that consumers with destiny beliefs and growth beliefs prefer to give different types of gifts for their significant others. Therefore, marketers can improve the effectiveness of their communication strategies by customizing their gifts based on the implicit theories of different consumers. Since we show that the implicit theories of relationship can be primed, marketers can use this to their advantage. Specifically, retailers who are marketing gift items higher on feasibility attributes can prime destiny beliefs in their promotion messages to motivate consumers to buy those products for their significant others. On the other hand, retailers who are marketing gift items higher on desirability attributes can prime growth beliefs in their promotion messages to motivate consumers to buy those products for their significant others.

\section{Limitations and future research}

Even though this research has important implications for theory and practice, it is not without limitations. This research shows that implicit theories of relationship influence consumers' gift-giving preferences. However, this research investigated gift-giving preferences only in the domain of an experience, specifically a restaurant gift certificate. Future research could test the generalizability of our findings by investigating if implicit theories of relationship influence consumers' gift-giving preferences in other consumption domains. Future research could also investigate the boundary conditions to this influence. For example, future research could investigate how time scarcity moderates the impact of implicit theories of relationships on consumers' gift-giving preferences. Specifically, since time scarcity influences consumers' product preference (Zauberman and Lynch, 2005), consumers with growth belief could pick a feasible gift if they feel that their significant others don't have enough time to consume the desirable gift. Pursuing these lines of inquiry could provide further insights into the role that implicit theories of relationship play in influencing consumer behavior.

\section{References}

Andrews, J. and Smith D.C. (1996), "In search of marketing imagination: Factors affecting the creativity of marketing programs for mature products", Journal of Marketing Research, Vol. 33, No. 2, pp. 174-187.

Baskin, E., Wakslak, C.J., Trope, Y and Novemsky, N. (2014), "Why feasibility matters more to gift receivers than to givers: A construal-level approach to gift giving", Journal of Consumer Research, Vol. 41, No. 1, pp. 169-182.

Belk, R.W. (1979), “Gift-giving behavior”, in Sheth, J. (ed.) Research in Marketing, Vol. 2, pp. 95-126, JAI press, Greenwich, CT.

Belk, R.W. and Coon, G.S. (1991), "Can't buy me love: Dating, money, and gifts", ACR North American Advances.

Buhrmester, M. Kwang, T. and Gosling, S.D. (2011), “Amazon's mechanical turk: A new source of inexpensive, yet high-quality, data?", Perspectives on Psychological Science, 
Vol. 6 No. 1, pp. 3-5.

Caplow, T. (1982), "Christmas gifts and kin networks”, American Sociological Review, pp. 383-392.

Cobb, R. A., DeWall, C. N., Lambert, N. M., \& Fincham, F. D. (2013), "Implicit theories of relationships and close relationship violence: does believing your relationship can grow relate to lower perpetration of violence?", Personality and Social Psychology Bulletin, Vol. 39, No. 3, pp. 279-290.

Dweck, C. S. (2000), Self-Theories: Their Role in Motivation, Personality, and Development. Psychology Press. Philadelphia, PA.

Elliott, E. S. and Dweck, C.S. (1988), "Goals: An approach to motivation and achievement", Journal of Personality and Social Psychology, Vol. 54 No.1, pp. 5-12.

Gino, F. and Flynn, F.J. (2011), "Give them what they want: The benefits of explicitness in gift exchange”, Journal of Experimental Social Psychology, Vol. 47, No. 5, pp. 915-922.

Goodman, J.K., Cryder, C. E. and Cheema, A. (2013), "Data collection in a flat world: The strengths and weaknesses of mechanical turk samples", Journal of Behavioral Decision Making, Vol. 26, pp. 213-224.

Hair, J. F., Black, W. C., Babin, B. J., Anderson, R. E., \& Tatham, R. L. (1998), Multivariate data analysis, Vol. 5, No. 3, Upper Saddle River, NJ: Prentice Hall.

Hayes, A.F. (2013), Introduction to mediation, moderation, and conditional process analysis: A regression-based approach, Guilford Press, New York.

Hui, C.M., Bond, M.H. and Molden, D.C. (2012), "Why do (n't) your partner's efforts at selfimprovement make you happy? An implicit theories perspective", Personality and Social Psychology Bulletin, Vol. 38, No. 1, pp. 101-113.

Knee, C.R. (1998), "Implicit theories of relationships: Assessment and prediction of romantic relationship initiation, coping, and longevity", Journal of Personality and Social Psychology, Vol. 74, No. 2, pp. 360-370.

Knee, C.R., Patrick, H. and Lonsbary, C. (2003), "Implicit theories of relationships: Orientations toward evaluation and cultivation", Personality and Social Psychology Review, Vol. 7, No. 1, pp. 41-55.

Knee, C.R., Nanayakkara, A., Vietor, N.A., Neighbors, C. and Patrick, H., (2001), "Implicit theories of relationships: Who cares if romantic partners are less than ideal?", Personality and Social Psychology Bulletin, Vol. 27, No. 7, pp. 808-819.

Liu, W. (2008), "Focusing on desirability: The effect of decision interruption and suspension on preferences", Journal of Consumer Research, Vol.35 No.4, pp. 640-652.

Mittal, B. (1994), "An Integrated framework for relating diverse consumer characteristics to supermarket coupon redemption", Journal of Marketing Research, Vol. 31, No. 4, pp. 533-44.

Nguyen, H.P. and Munch, J.M. (2011), "Romantic gift giving as chore or pleasure: The effects of attachment orientations on gift giving perceptions", Journal of Business Research, Vol. 64, No. 2, pp. 113-118.

Prendergast, C. and Stole L. (2001), "The non-monetary nature of gifts", European Economic Review, Vol. 45, No. 10, pp. 1793-1810.

Rai, D., Lin, C.W. and Ierlan, M.T. (2016), "The influence of scheduling style on assortment size", Management and Marketing, Vol. 11, No. 4, pp. 553-565.

Research and Markets (2015), "Gifting report 2015", available at: www.researchandmarkets.com/research/hq2wt4/gifting_report (accessed October, 6, 2017). 
Roscoe, J.T. (1975) Fundamental Research Statistics for the Behavioural Sciences, $2^{\text {nd }}$ edition, Holt Rinehart \& Winston, New York.

Ruth, J.A., Brunel, F.F. and Otnes, C.C. (2004), "An investigation of the power of emotions in relationship realignment: The gift recipient's perspective", Psychology \& Marketing, Vol. 2, No. 1, pp. 29-52.

Sherry, J.F. (1983), "Gift giving in anthropological perspective", Journal of Consumer Research, Vol. 10, No. 2, pp. 157-168.

Trope, Y. and Liberman, N. (2010), "Construal-level theory of psychological distance", Psychological Review, Vol. 117, No. 2, pp. 440-463.

Ward, M.K. and Broniarczyk, S.M. (2011), "It's not me, it's you: How gift giving creates giver identity threat as a function of social closeness", Journal of Consumer Research, Vol. 38, No.1, pp. 164-181.

Zhao, X., Lynch, J.G. and Chen, Q. (2010), "Reconsidering Baron and Kenny: Myths and truths about mediation analysis", Journal of Consumer Research, Vol. 37, No. 2, pp. 197-206.

Zuberman, G. and Lynch, J.G. (2005), "Resource slack and propensity to discount delayed investments of time versus money", Journal of Experimental Psychology: General, Vol. 134, No. 1, pp. 23-37. 


\section{Appendix 1}

\section{Growth beliefs manipulation}

\section{Challenges and Obstacles Make Relationships Last Longer}

WASHINGTON - In his talk at the American Psychological Association's annual convention held at Washington D.C in August, Dr. George Medin, a relationship expert, argued that "the ideal relationship develops gradually over time where challenges and obstacles in a relationship can make love even stronger. A successful relationship is mostly a matter of learning to resolve conflicts with a partner and a successful relationship evolves through hard work and resolution of incompatibilities."

He reported numerous large longitudinal studies showing that challenges and obstacles in a relationship make love stronger. He also reported research findings showing that relationships are successful through hard work and resolution of incompatibilities.

\section{Destiny beliefs manipulation}

\section{Relationships Last Longer Only When You Find Compatible Partners}

WASHINGTON - In his talk at the American Psychological Association's annual convention held at Washington D.C in August, Dr. George Medin, a relationship expert, argued that "potential relationship partners are either compatible or they are not and successful relationship is mostly a matter of finding a compatible partner. Potential relationship partners are either destined to get along or they are not and relationships that do not start off well inevitably fail."

He reported numerous large longitudinal studies showing that relationships are successful because of compatible partners. He also reported research findings showing that relationships that do not start off well inevitably fail. 